\title{
The synergistic neurotoxins of palmyrah (Borassus flabellifer L.) flour
}

\author{
A. A. P. KEERTHI ${ }^{1}$, E. R. JANSZ ${ }^{1}$, S. EKANAYAKE ${ }^{1 *}$ and \\ G. A. S. PREMAKUMARA ${ }^{2}$ \\ ${ }^{I}$ Department of Biochemistry, Faculty of Medical Science, University of Sri Jayewardenepura, Gangodawila, \\ Nugegoda, Sri Lanka. \\ ${ }^{2}$ Herbal Technology Section, Industrial Technology Institute, 363, Bauddhaloka Mawatha, \\ Colombo 07, Sri Lanka. \\ *Corresponding author,Email: sagarikae@hotmail.com Tel: 094 -011-2803578
}

\begin{abstract}
Palmyrah (Borassus flabellifer L.) is consumed in various forms in different parts of Sri Lanka. Although a neurotoxic syndrome had been described in rats it is being consumed by humans. However, the chemical nature of the neurotoxin is unknown. Thus the objective of the present study was to determine the neurotoxic principle using palmyrah seed shoot and bioactivity directed separations. Two primary amines were isolated. These were not toxic individually but toxic when given together showing synergism. Studies of the amines by ${ }^{1} \mathrm{H}$ NMR and ${ }^{13} \mathrm{C}$-NMR showed a steroidal aglycone (spirostane) linked to a carbohydrate moiety containing three $\alpha$-rhamnosyl residues and a $\beta$-pyranosyl residue. Comparison with known spectral data showed that the $\beta$-pyranosyl is likely to be a $\beta$-glucosaminosyl which is probably in position 6 of glucose in one compound and most likely to be in the position 3 of glucose in the other. Synergism appears to be at two levels (i.e. at the absorption level) where the high content of neutral saponins present appears to be needed to facilitate absorption of the cationic toxin and at the point of action. The synergistic mechanism of the toxic amines remains to be explained.

(C) 2009 International Formulae Group. All rights reserved.
\end{abstract}

Keywords: Palmyrah, neurotoxin, spirostane, saponins, primary amine, synergism.

\section{INTRODUCTION}

The seed shoot of palmyrah (Borassus flabellifer L.) is eaten, boiled or dried (kottakilangu), but mainly made into flour by milling. This is used in the preparation of many traditional dishes consumed regularly in the North and East of Sri Lanka. The toxic effects of palmyrah flour were first reported in 1971 as a hepatotoxic effect in rats (Arseculeratne et al., 1971). The symptoms were: ruffled coat, apathetic animal, nodding movements of head and uncoordinated spasms of fore-limbs, erect animals on hind limbs, falling over backwards, ataxia and finally death (Arseculeratne et al., 1971). The causative effect was damage to the rat liver mitochondrial membrane (Pathmanathan et al.,
2001). This conclusion was supported by hyperammonaemia and low serum urea (Perera, 2004) and high serum aspartate aminotransferase (AST) (Sumudunie et al., 2004) in rats. Literature also reported neurotoxicity of palmyrah flour (Greig et al., 1980). According to their work neurotoxin was a tertiary amine-saponin of a molecular weight of 1400 (Greig et al., 1980). Toxicity studies carried out in the area of consumption (Arseculeratne et al., 1971) might have led to underutilization of palmyrah flour.

It was reported by Perera (2004) that on separation by ion-exchange chromatography (Dowex), the cationic (amine) fraction was not toxic to Wistar rats on oral administration, unless recombined with the 
neutral fraction which is saponin rich and non toxic (Wickramasekara and Jansz, 2003). This is indicative of a synergistic effect, which shows that the saponin rich neutral fraction is needed to disrupt the mucosal membrane (Francis et al., 2002), after which the effective toxin is absorbed. The flour could be detoxified by dry heat at $80{ }^{\circ} \mathrm{C}$ for $45 \mathrm{~min}$ but not with wet heat (Sumudunie et al., 2004). The toxin was not volatile but dry heating of palmyrah flour causes a marked loss of primary amines (Keerthi et al., 2002). It has to be noted that neurotoxicity in humans has not been reported, and if the structure of the toxin is known it could help expand use of an underutilized resource.

Thus the aim of the study was to solve nearly a four decade old problem viz., the chemical nature of the neurotoxin aided by bioassay directed separation using Wistar rat animal models.

\section{MATERIALS AND METHODS \\ Seed shoot and animals}

Palmyrah seed shoot samples $(\sim 10 \mathrm{~kg})$ were obtained from Kalpitiya area in the North-west of Sri Lanka and stored in a freezer $\left(<0{ }^{\circ} \mathrm{C}\right)$ until use. Moisture of seed shoots was determined using oven dry method (AOAC, 1984; YCO-010 Series, Gemmy Industrial Crop, Taiwan), before commencing extraction procedures.

Inbred male Wistar rats were obtained from Medical Research Institute, Borella, Sri Lanka. Animals were housed in University animal house under standard conditions. Ethical clearance was obtained for the animal experiments from Faculty of Medical Sciences, Ethical Committee before commencement of animal experiments (Ethical committee approval no: 23, 2006).

\section{Chemicals}

Grade of chemicals was selected according to the level of separation. General purpose reagents (GPR) were used in preliminary separations up to Medium Pressure Liquid Chromatography (MPLC). From this point onwards analytical grade or spectroscopic grade solvents were employed. Hexane, methylene chloride and methanol were obtained from BDH Poole, England. Ethyl acetate and ammonium hydroxide (specific gravity 0.88) were obtained from
Superchem products (Needham Market/Suffolk) England. Distilled water was obtained from "Manesty" distillation unit (Manesty Machine Ltd, England) and autoclaved before use in intra venous (IV) injections.

\section{Bioactivity directed isolation of active fractions and compounds \\ Medium pressure liquid chromatography (MPLC)}

Palmyrah seed shoots were subjected to the separation procedure given in Figure 1, taking care that each step was well below the detoxification temperature $\left(80^{\circ} \mathrm{C}\right)$. Palmyrah seed shoot extract freeze dried powder $(\sim 12 \mathrm{~g})$ was mixed with silica (Silica gel $\mathrm{G}_{60} 0.040$ $0.063 \mathrm{~mm}$, MERCK, Germany) and packed into a MPLC column ("Separo" column and FMI QD Lab Pump, Sweden). Crude extract of palmyrah seed shoots was tested using animal experiment (see under Animals studies). Compounds were eluted stepwise by modifying the method by Ariyasena et al. (2002a), using $250 \mathrm{ml}$ hexane, $250 \mathrm{ml}$ methylene chloride, $750 \mathrm{ml}$ ethyl acetate and $500 \mathrm{ml}$ methanol respectively. Any extractive remaining in the column was extracted using water. The solvent free extractives were obtained after evaporation of solvents at room temperature. These extractives were further subjected to freeze drying and weights of each fraction obtained. Since hexane and methylene chloride fractions were insoluble in water, single dose animal experiments (see under Animals studies) were carried out using solvent free ethyl acetate, methanol and water fractions only.

\section{Ion exchange column chromatography (IECC)}

The methanolic fraction was subjected to further separations as it contained the most potent neurotoxic fraction according to experimental results. A column was set up in order to separate positively charged amines from other components according to the results obtained from animal studies. An amberlite cation resin was used to separate the cationic, anionic and neutral fractions as reported previously (Perera, 2004). The fractions colleted were concentrated under reduced pressure using a rotary evaporator and their respective weights were obtained. 


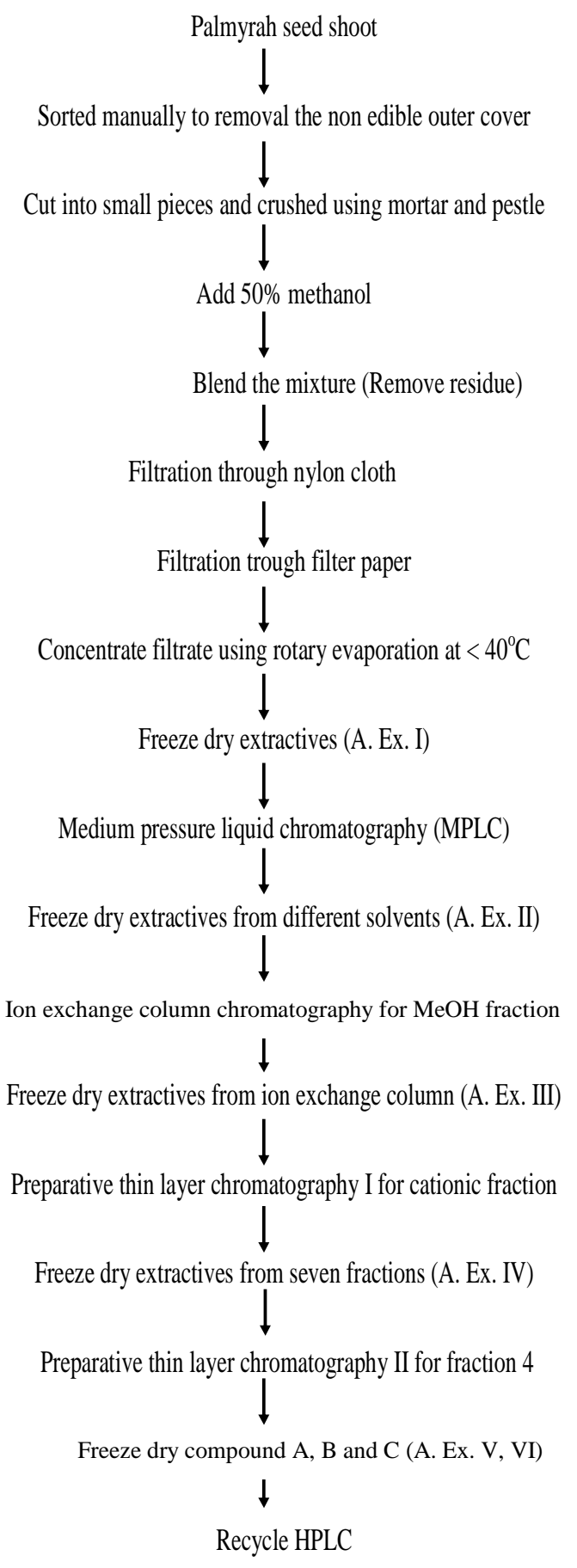

Figure 1: Flow diagram for separation of toxic synergists. A. Ex. number - Animal experiment number

\section{Thin layer chromatography (TLC)}

Cationic fraction obtained from ion exchange column chromatography (above) was subjected to preparative TLC-I (prepTLC-I). Preparative TLC plates (2-4 mm thickness) were prepared manually using silica gel $\mathrm{G}_{60} \mathrm{PF}_{254}$ (MERK, Germany). Separated fractions were introduced to several activated TLC plates in a horizontal line. Plates were developed using butanol: ethanol: ammonium hydroxide (BEN); 7: 5: 5 solvent system. Narrow bands were marked on TLC plate and each band was scraped and collected into separate tubes. Compounds/fractions were collected after re-extraction followed by evaporation of respective TLC bands. Separated solvent free fractions/compounds were then subjected to the animal experiments. According to the results of the animal experiment IV (under Animals studies) fraction No 4 (with 2-3 compounds), obtained from prepTLC-I was further separated by using preparative TLC-II (prepTLC-II) as above. Isolated compounds from prepTLC-II were named as compound A, B and C. These compounds were tested using animal experiments (under Animals studies). The fractions/compounds obtained during the above chromatographic separations were assessed using ninhydrin, anisaldehyde and other common spray reagents.

\section{Animal studies-Study of toxicity through intra-venous injections of specific freeze dried extractives \\ Male Wistar rats (body weight range} 215-430 g/8-12 weeks old) were used in experiments (I-VI see below) after an acclimatization period of one week. Rats were housed individually in polypropylene cages $(30 \times 22 \times 26 \mathrm{~cm})$ with a stainless steel lid with a fed hopper and bottle holder. Animals were fed with WHO standard rat and mouse breeding feed ad libitum and maintained under standard animal house conditions (Sabourdy, 1988). The separated compounds, after each chromatographic step (MPLC, IECC and TLC) were subjected to standard animal experiments. At least 5 animals were used in each experiment throughout this study, unless otherwise stated. Freeze dried extractives obtained during above separations were dissolved in distilled water and filtered using 0.45 micron syringe filter to prevent complications due to particles. Rats were given appropriate intravenous doses dissolved in less than $1 \mathrm{~mL}$ of water. The controls were 
given only distilled water. The doses for to the body weight of the animal and the ratio of the fractions with respect to its mother fraction. Immediately after dosing rats were observed for reported toxic symptoms at least for 6 hours/day.

Animal experiment I - for dose curve of methanol water extractives.

Animal experiment II - for hexane, methylene chloride, ethyl acetate, methanol and water extractives.

Animal experiment III - for cationic and neutral (and possibly anionic) fractions.

Animal experiment IV - for seven compound bands from prepTLC I.

Animal experiment $\mathrm{V}$ - for individual compound A, B and $\mathrm{C}$ obtained from prepTLC II.

Animal experiment VI - for mixture of compounds A and B (2:1 ratio).

Flow diagram for separation of toxic synergist and the conducted animal experiments are indicated in figure 1.

\section{Recycle HPLC}

The recycle HPLC was used to further purify the compounds. The separated compounds A and B (with two colourless fluorescent carotenoids as $5-10 \%$ impurity) were purified using recycle HPLC column GS 320 (GAIGEL, $21.5 \mathrm{~mm}$ i.d. $\times 500 \mathrm{~mm}$, Japan Analytical Industry Co. Ltd, Tokyo, Japan) with UV detector (JAI UV 310) and refractive index detector (RI-5). Isocratic flow rate was maintained at $5 \mathrm{~mL} / \mathrm{min}$ using 1:1 methanol: water mixture. An 8-10 mg sample of each compound dissolved in $3 \mathrm{ml}$ HPLC grade methanol was injected to HPLC. More than 6 cycles were conducted for better separations. The separated pure compounds were used for spectroscopic studies.

\section{Spectroscopy}

The compounds were dissolved in deuterated pyridine and subjected to NMR experiments (Tetramethylsilane/TMS as an internal reference). ${ }^{1} \mathrm{H}-\mathrm{NMR},{ }^{13} \mathrm{C}-\mathrm{NMR}$, DEPT, HMQC, HMBC and COSY [Distortionless enhancement by polarization transfer (DEPT), ${ }^{1} \mathrm{H}$-detected heteronuclear one-bond spectroscopy (HMQC), ${ }^{1} \mathrm{H}$-detected heteronuclear multiple-bond spectroscopy (HMBC) and two dimensional ${ }^{1} \mathrm{H}$-correlation spectroscopy (COSY)] experiments were animal experiments were calculated according conducted using Avance AV 600 and Avance AV 500 NMR spectrometers. Infra red spectra in $\mathrm{KBr}$ pellets were obtained using a Shimadzu IR 55 spectrophotometer.

\section{RESULTS \\ Bioactivity guided separation of neurotoxic compound \\ The moisture content of the raw} Palmyrah seed shoot was 51\%. A dose of 610 $\mathrm{mg} / \mathrm{kg} / \mathrm{rat} /$ day from freeze dried palmyrah seed shoot methanol: water (1: 1) extractives was found to be lethal to rats within 24 hours and $305 \mathrm{mg} / \mathrm{kg} / \mathrm{rat} /$ day indicated previously reported toxic symptoms (Animal experiment I). The toxic effects were dose dependent.

Successive MPLC extractions on solvent free methanol water extractives using hexane, methylene chloride, ethyl acetate, methanol and water produced 24, 68, 128, 8462 and $462 \mathrm{mg}$ of extractives per $1 \mathrm{~kg}$ raw seed shoot respectively. Experiments indicated that the solvent free methanolic extractive, which was water soluble to be neurotoxic and lethal within 24 hours to rats at a dose of $432 \mathrm{mg} / \mathrm{kg} / \mathrm{rat} /$ day (Table 1 / Animal experiment II). The prominent symptoms were ruffled coat, uncoordinated spasms, nodding movements of head and of fore-limbs followed by falling over backward and characteristic fits.

Separation of methanol fraction through ion exchange column chromatography yielded $2662 \mathrm{mg}$ of cationic fraction and $3752 \mathrm{mg}$ of neutral (and possibly anionic) fractions for one kilogram of seed shoot. The cationic fraction contained a ninhydrin positive spot which coincided with an anisaldehyde positive spot on TLC with BEN 7: 3: 4 solvent system, while the anionic fraction gave the typical TLC spots of saponins and low retardation factor $\left(\mathrm{R}_{\mathrm{f}}\right)$ ninhydrin positive spots. Animals administered the cationic fraction intravenously showed the neurotoxic symptoms and death resulted within one day at a dose of $150 \mathrm{mg} / \mathrm{kg} / \mathrm{rat} /$ day (Animal experiment III). The toxic symptoms and behavior observed from two test groups and control animals were remarkably different.

On prepTLC-I, seven fractions separated and only one fraction (fraction 4) 
Table 1: Neurotoxic effects of rats treated with different MPLC extracts of palmyrah seed shoot $\mathrm{MeOH}$ water extractive.

\begin{tabular}{|c|c|c|c|c|}
\hline $\begin{array}{l}\text { Extract } \\
\text { (No of animals) }\end{array}$ & $\begin{array}{c}\text { Dose } \\
\mathrm{mg} / \mathrm{kg} / \mathrm{rat} / \text { day * }\end{array}$ & 6 hours & Day 1 & Day2 \\
\hline $\begin{array}{l}\text { Water } \\
(\mathrm{n}=7)\end{array}$ & 170 & 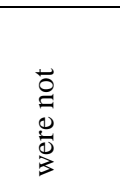 & $\begin{array}{l}\text { Rats were not normal, } \\
\text { high excitation, food } \\
\text { consumption }<5 \text { g/day }\end{array}$ & $\begin{array}{c}\text { Rats were normal, } \\
\text { with normal food } \\
\text { consumption }\end{array}$ \\
\hline $\begin{array}{l}\text { Methanol } \\
(\mathrm{n}=7)\end{array}$ & 432 & 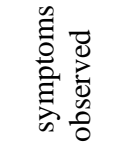 & $\begin{array}{l}4 \text { rats dead, } 3 \text { rats with all } \\
\text { neurotoxic symptoms, } \\
\text { Not food consumption. }\end{array}$ & $\begin{array}{l}5 \text { rats dead } 2 \text { rats } \\
\text { remained alive with very } \\
\text { low food consumption }\end{array}$ \\
\hline $\begin{array}{l}\text { Ethyl acetate } \\
(\mathrm{n}=7)\end{array}$ & 3.7 & . & \multirow{2}{*}{\multicolumn{2}{|c|}{$\begin{array}{l}\text { Neurotoxic symptoms } \\
\text { were not observed }\end{array}$}} \\
\hline $\begin{array}{l}\text { Control } \\
(\mathrm{n}=7)\end{array}$ & Nil & & & \\
\hline
\end{tabular}

Table 2: Neurotoxic effects of rats treated with different fractions obtained through preparative TLC I (prepTLC-I).

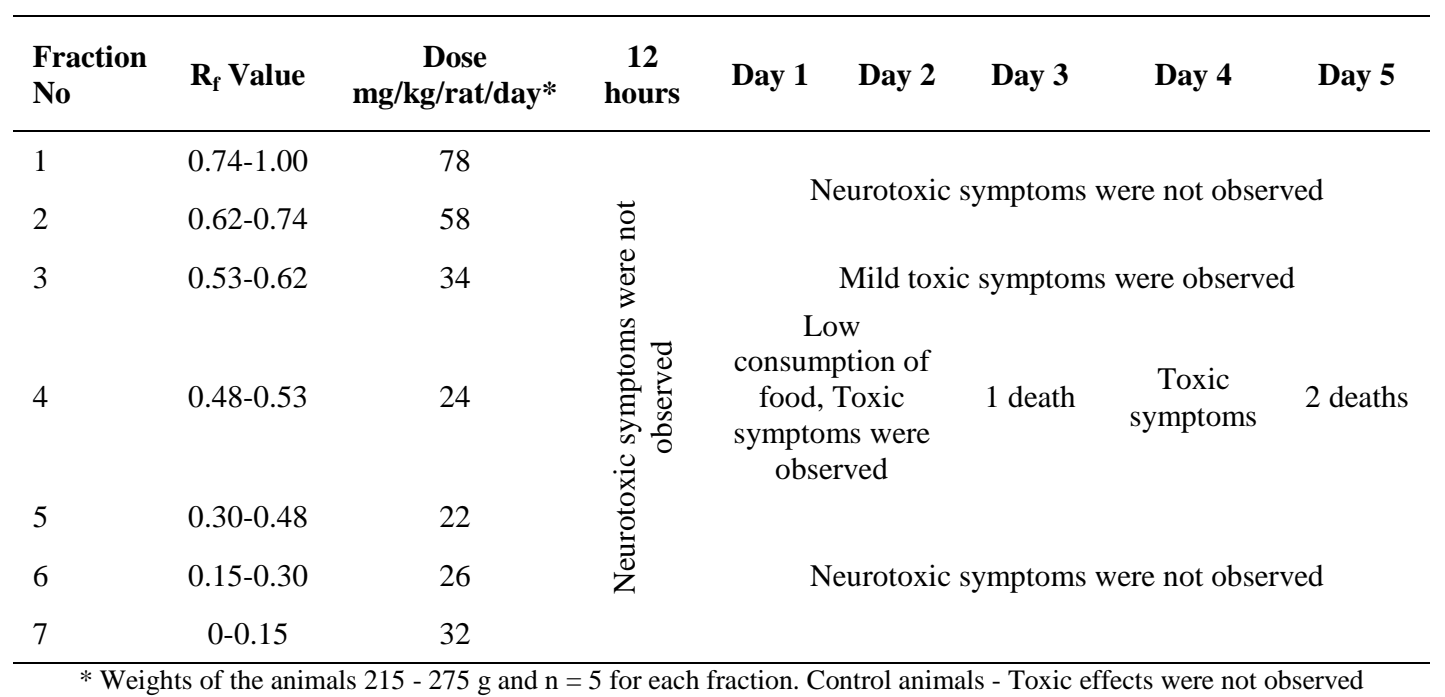

had neurotoxic effect (Table 2 / Animal experiment IV). Further separation of this fraction on prepTLC-II yielded three compounds namely $\mathrm{A}, \mathrm{B}$ and $\mathrm{C}$ at $\mathrm{R}_{\mathrm{f}} 0.65$, 0.72 and 0.69 respectively (BEN 7: 5: 5). Compound A and B were ninhydrin positive. None of the compounds were positive to Dragendorff's reagent for tertiary amines. The compound $\mathrm{C}$ was inactive to anisaldehyde, phosphomolybdic acid and iodine vapour. The ratio of weights of above three compounds $\mathrm{A}$ : B: C was 211:100:28 w/w. Compounds A and
B were stable throughout the entire isolation procedure.

\section{Neurotoxic synergism}

Pure compounds A, B and C were water soluble. None of them when intravenously administered singly caused neurotoxicity (Animal experiment V). However, recombination of compounds $\mathrm{A}$ and B (2:1 ratio) showed neurotoxicity at a dose of $62 \mathrm{mg} / \mathrm{kg} / \mathrm{rat} / \mathrm{day}$. A dose of 115 $\mathrm{mg} / \mathrm{kg} / \mathrm{rat} / \mathrm{day}$, from above mixture was lethal 
to rats (Animal experiment VI). Palmyrah flour usually contains compounds $\mathrm{A}$ and $\mathrm{B}$ in a ratio of 2: 1. Ruffled coat, uncoordinated spasms and erect immobilized animals were among prominent symptoms observed in treated rats. The toxic effects diminished after termination of dosing.

\section{Spectroscopic studies}

Pure compounds were obtained using reverse phase recycle HPLC. Pure compounds $\mathrm{A}$ and $\mathrm{B}$ were ninhydrin positive. IR spectra had a very broad peak around $3500 \mathrm{~cm}^{-1}$ for $\mathrm{OH}$ groups in the sugar moieties for both compounds. The comparison of ${ }^{1} \mathrm{H}-\mathrm{NMR}$
(Figure 2) and ${ }^{13} \mathrm{C}-\mathrm{NMR}$ spectra of aglycone of compound $\mathrm{A}\left(\mathrm{R}_{\mathrm{f}}-0.65\right)$ with that of a compound isolated from palmyrah flower (inflorescence) by Yoshikawa et al. (2007) is given in Table 3. Comparison clearly suggested spirostane ring structure for compound $\mathrm{A}$. The main differences of $\mathrm{A}$ and $B$ were at the signals for anomeric protons (Table 4). Spectral data obtained for ${ }^{13} \mathrm{C}$ NMR of the compound A were identical to the spectral data reported by Yoshikawa et al. (2007), except for the first sugar moiety (Glc). Signal corresponding to position six of the Glc appears around $\delta 61$ in ${ }^{13} \mathrm{C}-\mathrm{NMR}$ (Yoshikawa

Table 3: ${ }^{13} \mathrm{C}$ and ${ }^{1} \mathrm{H}-\mathrm{NMR}$ comparison for aglycones of two molecules.

\begin{tabular}{|c|c|c|c|c|}
\hline \multirow{2}{*}{ Carbon Number } & \multicolumn{2}{|c|}{ Yoshikawaet al., 2007} & \multicolumn{2}{|c|}{ This study } \\
\hline & $\delta_{\mathbf{H}}(J \mathbf{H z})$ & $\boldsymbol{\delta}_{\mathrm{C}}$ & $\delta_{\mathbf{H}}(J \mathbf{H z})$ & $\boldsymbol{\delta}_{\mathbf{C}}$ \\
\hline 1 & $0.98(\mathrm{~m}), 1.72(\mathrm{~m})$ & 37.6 & $0.97(\mathrm{~m}), 1.72(\mathrm{~m})$ & 37.5 \\
\hline 2 & $1.83(\mathrm{~m}), 2.07(\mathrm{~m})$ & 30.2 & $1.83(\mathrm{~m}), 2.04(\mathrm{~m})$ & 29.9 \\
\hline 3 & $3.86(\mathrm{~m})$ & 78.1 & $3.87(\mathrm{~m})$ & 78.0 \\
\hline 4 & $\begin{array}{c}2.70(\mathrm{dd}, 11.5,13.2) \\
2.79(\mathrm{dd}, 3.8,13.2)\end{array}$ & 39.1 & $\begin{array}{l}2.71(\mathrm{dd}) \\
2.79(\mathrm{dd})\end{array}$ & 38.9 \\
\hline 5 & & 141.0 & & 140.8 \\
\hline 6 & $5.33($ br d, ca 5) & 121.8 & $5.33($ br d $)$ & 121.8 \\
\hline 7 & $1.51(\mathrm{~m}), 1.89(\mathrm{~m})$ & 32.5 & $1.48(\mathrm{~m}), 1.85(\mathrm{~m})$ & 32.2 \\
\hline 8 & $1.52(\mathrm{~m})$ & 31.6 & $1.62(\mathrm{~m})$ & 31.6 \\
\hline 9 & $0.89(\mathrm{~m})$ & 50.5 & $0.86(\mathrm{~m})$ & 50.3 \\
\hline 10 & & 37.2 & & 37.1 \\
\hline 11 & $1.44(\mathrm{~m}), 1.08(\mathrm{~m})$ & 21.2 & $1.35(\mathrm{~m})$ & 21.1 \\
\hline 12 & $1.69(\mathrm{~m})$ & 40.4 & $1.68(\mathrm{~m})$ & 39.8 \\
\hline 13 & & 41.1 & & N/D \\
\hline 14 & $0.97(\mathrm{~m})$ & 55.9 & N/D & 55.6 \\
\hline 15 & $1.47(\mathrm{~m}), 2.02(\mathrm{~m})$ & 33.3 & $1.48(\mathrm{~m}), 1.85(\mathrm{~m})$ & 32.1 \\
\hline 16 & $4.31(\mathrm{~m})$ & 80.9 & $4.44(\mathrm{~m})$ & 80.4 \\
\hline 17 & $1.59(\mathrm{dd}, 7.3,8.3)$ & 62.7 & $1.78(\mathrm{~m})$ & 62.7 \\
\hline 18 & $0.97(\mathrm{~s})$ & 16.7 & $0.80(\mathrm{~s})$ & 16.3 \\
\hline 19 & $1.04(\mathrm{~s})$ & 19.4 & $1.03(\mathrm{~s})$ & 19.4 \\
\hline 20 & $2.32(\mathrm{~m})$ & 42.2 & N/D & 42.4 \\
\hline 21 & $1.02(\mathrm{~d}, 6.9)$ & 16.8 & $0.81(\mathrm{~d}, 5.5)$ & 16.3 \\
\hline 22 & & 110.7 & & 109.7 \\
\hline 23 & $1.68(2 \mathrm{H}, \mathrm{m})$ & 28.4 & N/D & N/D \\
\hline 24 & $1.57(2 \mathrm{H}, \mathrm{m})$ & 28.2 & $\mathrm{~N} / \mathrm{D}$ & 27.5 \\
\hline 25 & $1.63(\mathrm{~m})$ & 30.8 & N/D & 30.1 \\
\hline 26 & $3.68(2 \mathrm{H}, \mathrm{d}-\mathrm{like})$ & 69.7 & $3.63(\mathrm{~m})$ & 70.4 \\
\hline 27 & $0.70(\mathrm{~d}, 6.3)$ & 17.3 & $0.67(\mathrm{~d}, 5.2)$ & 17.3 \\
\hline
\end{tabular}


Table 4: Comparison of the anomeric protons of compound A and B.

\begin{tabular}{|c|c|c|}
\hline $\begin{array}{l}{ }^{1} \mathrm{H}-\mathrm{NMR} \text { Chemical } \\
\text { shift of Compound A }\end{array}$ & $\begin{array}{l}{ }^{1} \text { H-NMR Chemical } \\
\text { shift of Compound B }\end{array}$ & Anomeric structure \\
\hline 4.9 (d) $J=9.2 *$ & 4.6 (d) $J=8.7^{*}$ & $\beta$-pyranoside \\
\hline 5.8 (br s) $J<1.8$ & $5.8(\mathrm{br} \mathrm{s})$ & $\alpha$-rhamnoside \\
\hline 6.4 (br s) $J<1.8$ & $6.4(\mathrm{br} \mathrm{s})$ & $\alpha$-rhamnoside \\
\hline $6.2($ br s) $J<1.8$ & $6.2(\mathrm{br} \mathrm{s})$ & $\alpha$-rhamnoside \\
\hline
\end{tabular}

* The anomeric protons of the $\beta$-pyranoside differ.

et al., 2007). This was not observed in the spectrum of compound A possibly because of Glc moiety. It can be concluded that the neurotoxic synergists A and B are steroidal saponins with a spirostane ring system containing a primary amine group probably in the sugar moiety of 4 units comprising, three$\alpha$-rhamnosyl and a $\beta$-pyranosyl which is not glucose.

\section{DISCUSSION}

Traditionally palmyrah flour is made by grinding sun dried or boiled and sun dried palmyrah seed shoots (Balasubramanium et al., 1999). In this study raw seed shoots were used as the starting material to avoid loss of compounds due to processing. The separation protocols were designed to ensure that the processing temperature was below $40{ }^{\circ} \mathrm{C}$. This is important as the toxin is known to be destroyed at $80{ }^{\circ} \mathrm{C}$ (Sumudunie et al., 2004). The anionic fraction resulting from ion exchange chromatography contained a high concentration of neutral saponins compared to its cationic fraction. Saponins are capable of damaging biological membranes (Francis et al., 2002). According to Perera cationic fraction is non-toxic when administered orally to Wistar rats (Perera, 2004), but in this study it was found to be toxic when given intravenously. This suggested that the high concentration of the neutral steroids (Wickramasekara and Jansz, 2003) act to facilitate the entry of the cationic toxin in to the blood stream, by damaging the gut mucous membrane.

The mild toxic symptoms observed in fraction $\mathrm{n}^{\circ} 3$ probably due to a residual effect. Repeated studies on this fraction confirmed absence of specific toxic constituents. Toxic symptoms were observed with the mixture of compound $\mathrm{A}$ and $\mathrm{B}$ (2:1 ratio) at a concentration of $62 \mathrm{mg} / \mathrm{kg} / \mathrm{rat} / \mathrm{day}$. However toxic symptoms were not observed when compounds A and B were administered separately at a dose of 100 and 172 $\mathrm{mg} / \mathrm{kg} / \mathrm{rat} /$ day respectively, clearly showing synergistic action.

Naturally occurring ratio of compound A, B and C was found to be 211:100:28. A dose of $24 \mathrm{mg} / \mathrm{kg} / \mathrm{rat} / \mathrm{day}$ from fraction 4 (Animal experiment IV), which contained all three compounds was lethal to rats. If the appeared toxicity is due to compound $\mathrm{C}$, the effective dose for which can be calculated as approximately $2 \mathrm{mg} / \mathrm{kg} / \mathrm{rat} / \mathrm{day}$. However, a separate experiment indicated that the compound $\mathrm{C}$ alone is not toxic even at a dose as high as $40 \mathrm{mg} / \mathrm{kg} / \mathrm{rat} /$ day. However, the possible contribution of compound $\mathrm{C}$ in enhancing synergism cannot be ruled out.

The compounds $\mathrm{A}$ and $\mathrm{B}$ were ninhydrin positive. The most probable site for an amino group is replacement of a glucosyl $\mathrm{OH}$. Glucosamines are readily available in plants; such molecules can be easily incorporated into secondary metabolites during their biosynthesis. The ${ }^{1} \mathrm{H}$ NMR spectra of compound A and B are similar apart from a chemical shift observed in the ${ }^{1} \mathrm{H}$ NMR signals of anomeric protons. Flabelliferins or Borassoside found in palmyrah usually contain $\beta$-glucose as the first sugar moiety attached to the aglycone (Nikawala et al., 2000; Ariyasena et al., 2002b; Yoshikawa et al., 2007). Generally in ${ }^{1} \mathrm{H}$ NMR the anomeric proton of $\beta$ glucopyranosyl appears around $\delta 4.2$ to 4.4 
(Bax et al., 1984). However, in compounds A and $\mathrm{B}$, a shift has occurred from the normal value to $\delta 4.9$ and 4.6 respectively. Therefore it is likely that the $\mathrm{NH}_{2}$ is found in both $\mathrm{A}$ and $\mathrm{B}$ residues on the $\beta$-pyranosyl moiety but differing in the position of attachment. The primary amine is most likely to be in position 6 ' of the $\beta$-pyranosyl of $A$ in view of the absence of ${ }^{13} \mathrm{C}$ NMR peak within $\delta$ values of 61-63, which corresponds to C-6 of glucopyranosyl. With above spectral evidences and HMBC correlations for the compound A (Figure 4), the structure of $\mathrm{A}$ is tentatively suggested as in figure 5 .

Similarity of ${ }^{1} \mathrm{H}$ NMR of compound B (Figure 3 ) to that the ${ }^{1} \mathrm{H}$ NMR of compound A suggested similar structures except for $\mathrm{NH}_{2}$ group. The position $3^{\prime}$ on $\beta$-pyranosyl in compound $\mathrm{B}$ can be hypothesized as a favorable site for $\mathrm{NH}_{2}$ group even without spectral evidences. This hypothesis cannot be ruled out by available spectral data. It is necessary to highlight that the proposed structures through our findings agree with most of previous reports on the nature of compound causing neurotoxicity. However, more detailed studies on chemistry and the mechanism of action of compounds should be further studied.

There is evidence of neurotoxic effects on the mitochondrial membrane in liver mitochondria (Pathmanathan, 2001). However, the neurotoxic symptoms suggest that mitochondria of the other tissues may be affected, notably that of the nervous system. This damage to the neurons would cause a deficit of ATP which would explain the neurotoxic symptoms, which were clearly

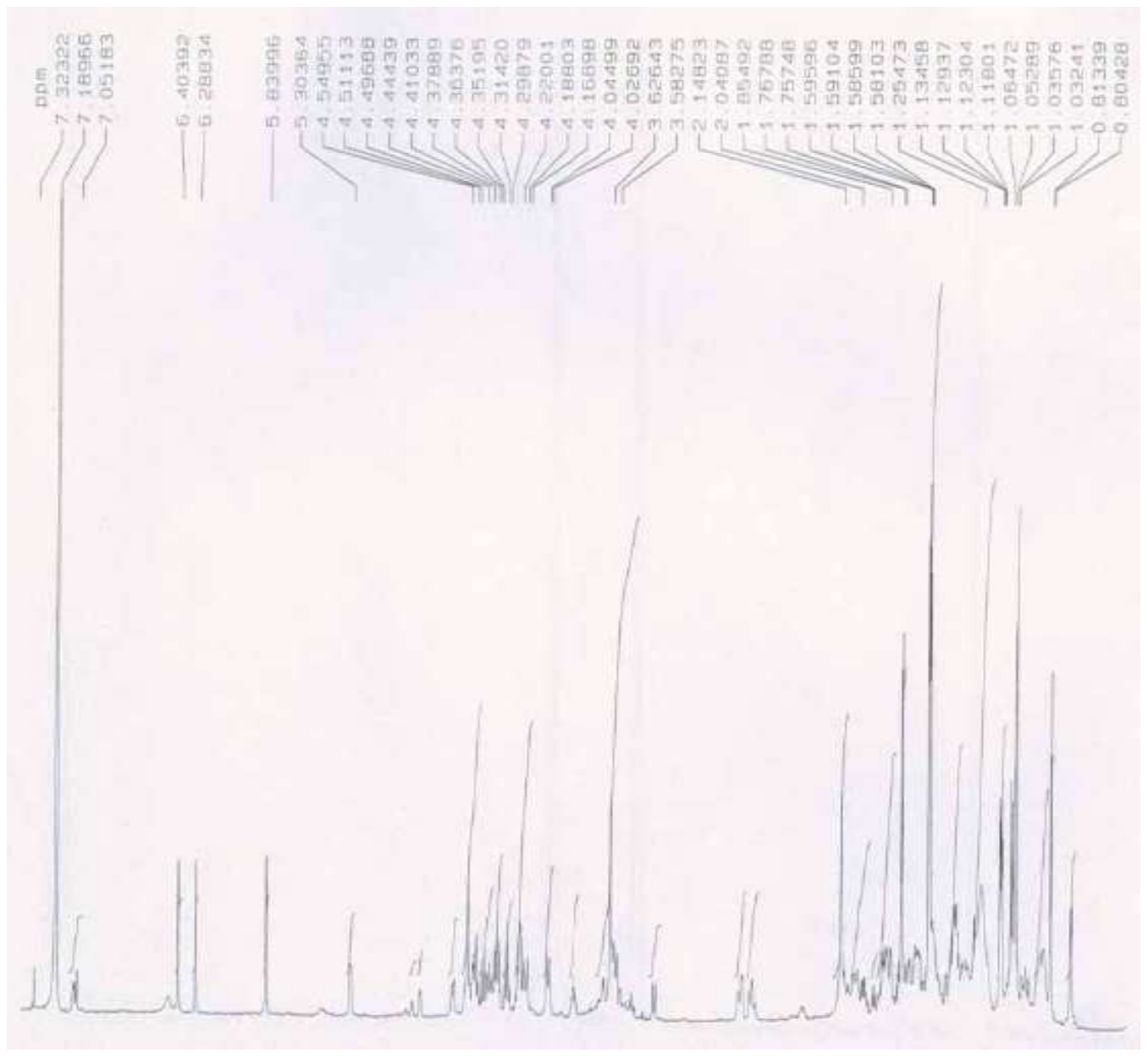

Figure 2: ${ }^{1} \mathrm{H}-\mathrm{NMR}$ spectrum of the compound A (Rf - 0.65). 
A. A. P. KEERTHI et al. / Int. J. Biol. Chem. Sci. 3(2): 255-265, 2009

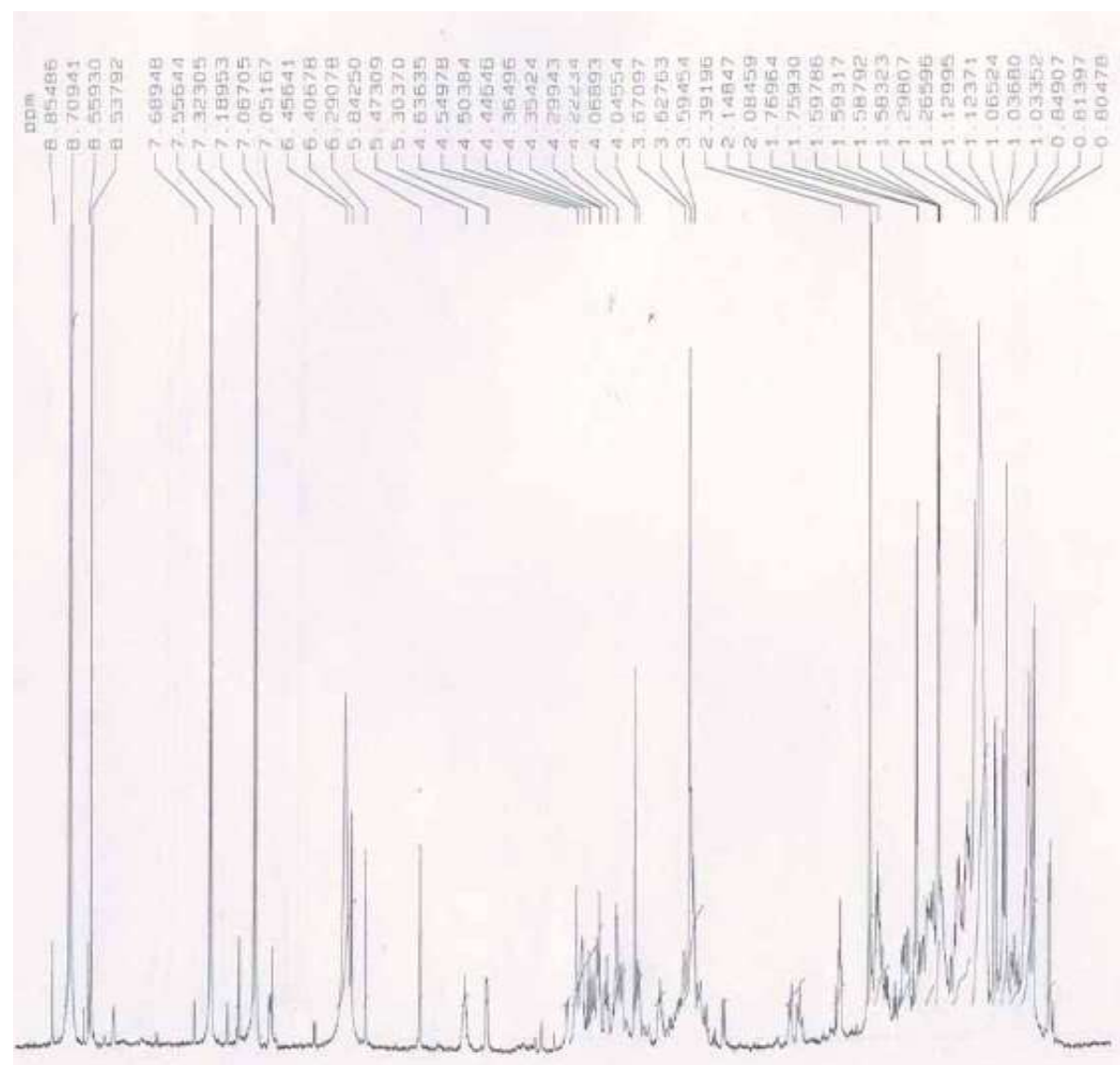

Figure 3: ${ }^{1} \mathrm{H}-\mathrm{NMR}$ spectrum of the compound B (Rf - 0.72).

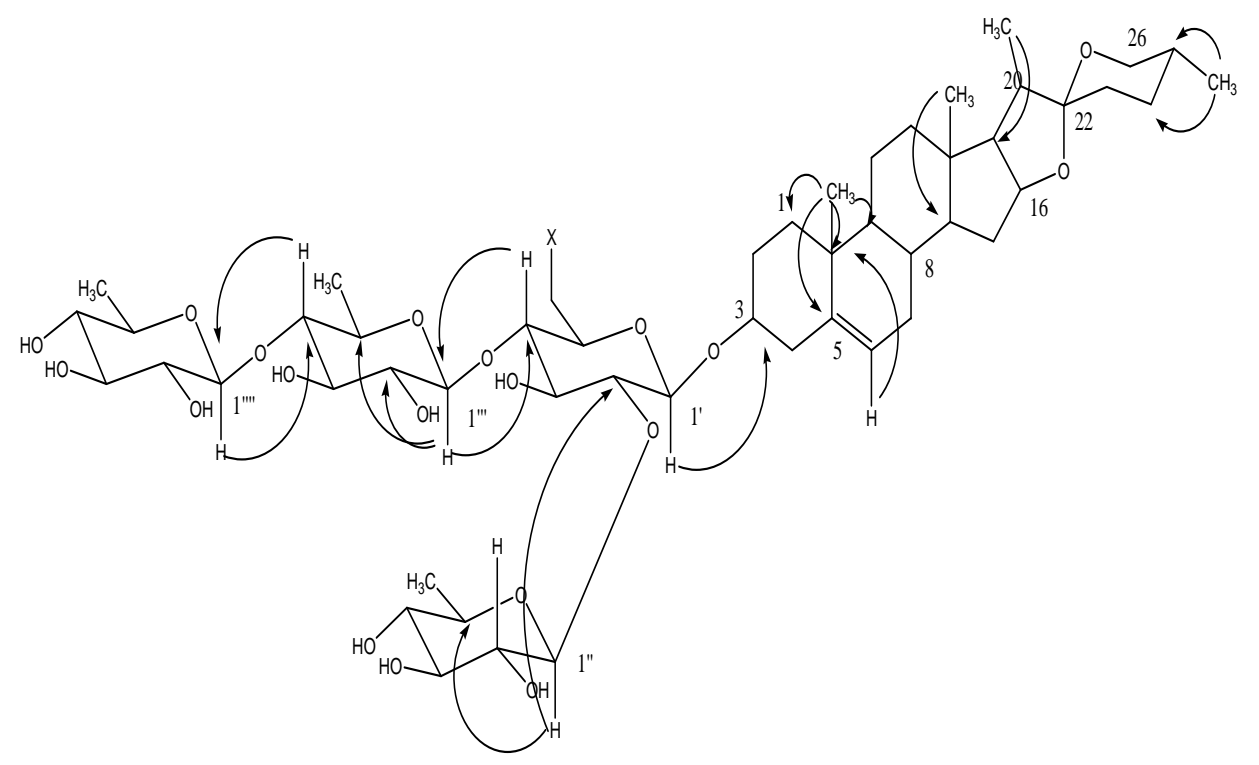

Figure 4: HMBC correlations of neurotoxic compound A. 


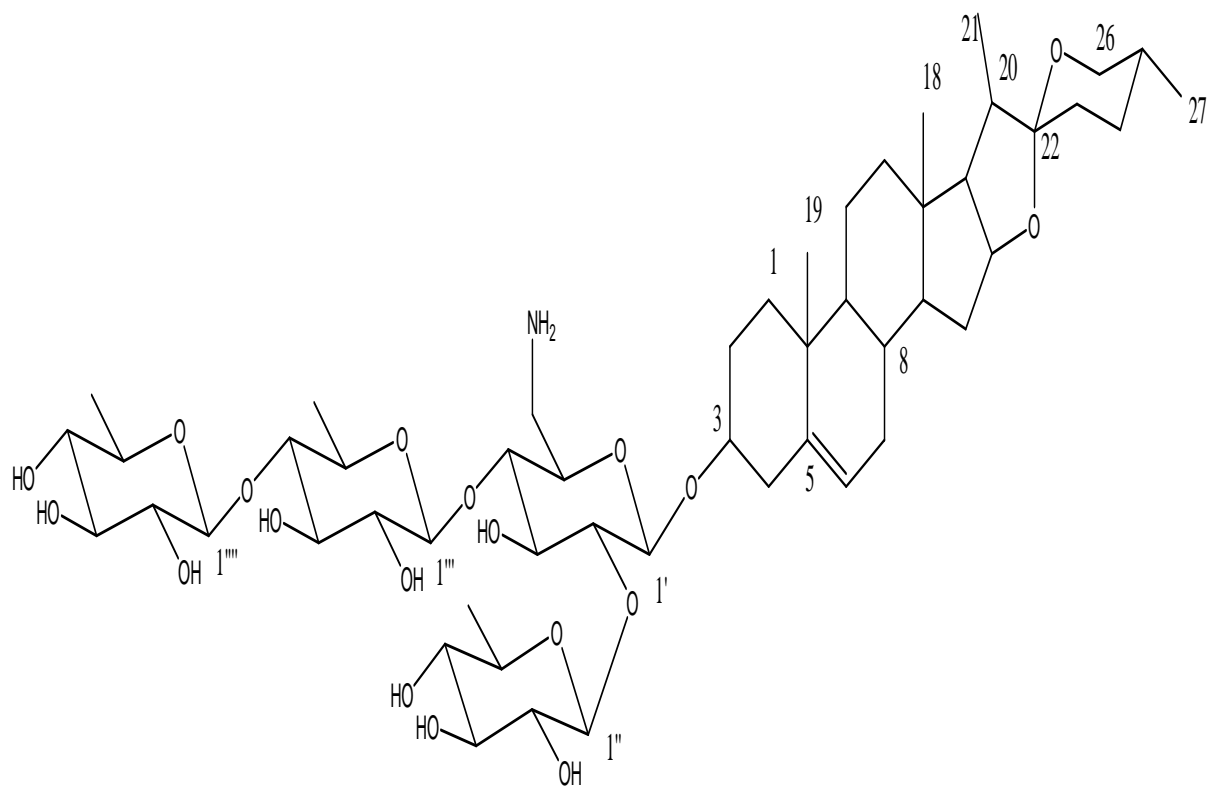

Figure 5: Tentative structure of the neurotoxic compound A.

observed in the above experiments. There are numerous papers to support neurotoxicity as well as hepatotoxicity in rats. But during this study based on our earlier experience and observations, we focused on the very early toxic symptoms which are parallel with other neurotoxicity screening batteries (Kram and Keller, 2001). During the study toxic symptoms appeared within 6-12 hours and death resulted within 24 hours, which is unlikely to be in the case of a hepatotoxicity (Schoental, 1968) but could be due to neurotoxicity (Yeh, 1997).

This study clearly indicates that the toxic compounds are water soluble. Therefore during food processing, detoxification of palmyrah flour can be achieved by washing in addition to heating flour above $80{ }^{\circ} \mathrm{C}$. The washing step can be seen in traditional palmyrah flour food preparations (Balasubramanium et al., 1999). This study provides another possible reason in addition to temperature why neurotoxicity is not reported in the human population. All above findings should encourage the use of underutilized palmyrah flour in food preparations; the processing of which is now in the hands of a section of a population which is economically deprived.

\section{ACKNOWLEDGEMENTS}

The authors thank Prof. Muhammad Iqbal Choudhary, HEJ Research Institute of Chemistry, University of Karachi, Pakistan, for the spectroscopic facilities provided and IPICS, Uppsala University, Sweden for Grant No: SRI: 07 and National Science Foundation of Sri Lanka for Grant No: RG/2004/C/06.

\section{REFERENCES}

AOAC (Association of Official Analytical Chemistry). 1984. Official Methods of Analysis $7.003\left(14^{\text {th }}\right.$ edn). Association of Official Analytical Chemistry: Virginia DC.

Ariyasena DD, Jansz ER, Baeckstrom P. 2002a. Directisolation of flabelliferins of palmyrah by MPLC. J. Natn Sci. Foundation Sri Lanka, 30: 55-60.

Ariyasena DD, Jansz ER, Janssen PE, Baeckstrom P. 2002b. Structural elucidation of the antimicrobial flabelliferin from palmyrah (Borassus flabellifer L.) fruit pulp. Chemistry in Sri Lanka, 19: 13-14.

Arseculeratne SN, Panabokke RG, Tennakoon GE, Bandunatha CHSR. 1971. Toxic effects of Borassus flabellifer (Palmyrah 
palm) in rats. Br. J. of Exp. Path., 52: 524-537.

Balasubramanium K, Jansz ER, Ariyasena DD. 1999. Palmyrah: The International Program in Chemical Science (IPICS) ISBN 955-96690-0-1; 1-38.

Bax A, Egan W, Kowac P. 1984. New NMR techniques for structure determination and resonance assignment of complex carbohydrates. J. of Carbohydrate Chem., 5: 593-611.

Francis G, Kerem Z, Makkar HPS, Becker K. 2002. The biological action of Saponin in animal systems: a review. Br. J. of Nutr., 88: 587-605.

Greig JB, Kay SJE, Bennetts RJ. 1980. A toxin from the palmyrah palm, Borassus flabellifer: Partial purification and effects in rats. Fd. Cosm. Toxicol., 18: 483-488.

Keerthi AAP, Van der Hoevan R, Nikawala JK, Jansz ER. 2002. Studies on the effect of the heat on the neurotoxic factor of palmyrah flour. Vid. J. of Sci., 11: 79-85.

Kram DJ, Keller KA. 2001. Toxicology Testing Hand Book Principles, Applications and Data Interpritation $\left(1^{\text {st }}\right.$ edn). Marcel Dekker: New York.

Nikawala JK, Jansz ER, Baeckstrom P, Abeysekara AM, Wijeyaratne SC. 2000. Flabelliferins of naringinase debittered palmyrah fruit pulp. Vid. J. of Sci., 9: 7986.

Pathmanathan R, Arseculeratne SN, Wong MH. 2001. The ultrastructure of palmyrah (Borassus flabellifer L.) - intoxicated mouse hepatocytes. The Ceylon Journal of Medical Science, 44: 35-40.

Perera PS. 2004. Toxicity studies on Borassus flabellifer flour and Amblygaster sirm. M.Phil. Thesis, Department of Biochemistry, University of Sri Jayewardenepura, Sri Lanka.

Sabourdy MA. 1998. Breeding and care of laboratory animals. WHO/Lab/88 1.1; 45.

Schoental R. 1968. Toxicology and carcinogenic action of pyrrolizidine alkaloids. Cancer Research, 28: 22372246.

Sumudunie KAV, Jansz ER, Jayasekera S, Wickramasinghe SMDN. 2004. The neurotoxic effect of palmyrah (Borassus flabellifer) flour re-visted. Int. J. of $F d$. Sci. and Nutr., 85: 607-614.

Wickramasekara NT, Jansz ER. 2003. The range of steroidal saponins of palmyrah flour: could they contribute to toxic effect on consumers. J. of Sci., Eastern University of Sri Lanka. 3: 11-18.

Yeh SY. 1997. Effects of salicylate on 3, 4Methylenedioxymethamphetamine (MDMA)-induced neurotoxicity in rats. Pharmacology Biochemistry and Behavior, 58(3): 701-708.

Yoshikawa M, Xu F, Morikawa T, Pongpiriyadacha Y, Nakamuru S, Asao Y, Kumahara A, Matsuda H. 2007. Medicinal flowers XII, new spirostanetype steroid saponins with antidiabetogenic activity from Borassus flabellifer. Chem. and Pharm. Bull., 55: 308-316. 